\title{
Performance Prediction of Niger Delta Reservoir BUZA Using Allocation Tool
}

\author{
Anthony Kerunwa, Obinna Anyanwu Chukwujioke \\ Department of Petroleum Engineering, School of Engineering and Engineering Technology, Federal University of Technology, Owerr, \\ Nigeria \\ Email address: \\ anthonykerunwa@rocketmail.com (A. Kerunwa)

\section{To cite this article:} \\ Anthony Kerunwa, Obinna Anyanwu Chukwujioke. Performance Prediction of Niger Delta Reservoir BUZA Using Allocation Tool. \\ International Journal of Oil, Gas and Coal Engineering. Vol. 7, No. 2, 2019, pp. 60-66. doi: 10.11648/j.ogce.20190702.13
}

Received: March 28, 2019; Accepted: May 15, 2019; Published: June 12, 2019

\begin{abstract}
Predicting the performance of reservoirs help engineers to evaluate reserves, carryout development planning which requires thorough understanding of the reservoir characteristics, develop a model that can mimic the physical processes occurring in the reservoir such that forecast can be made with reasonable accuracy. This study used the material balance software, MBAL which is an allocation tool to evaluate the reserves of reservoir Buza and thereafter predictions were carried out on the reservoir. This was achieved by determining the dominant energy in the reservoir, performing non-linear regression on the uncertain parameters and performance predictions to obtain cumulative oil production and recovery factor. The results obtained showed that water injection at an average rate of $22000 \mathrm{STB} / \mathrm{D}$ was the main energy in the reservoir providing about $68 \%$ of the total energy in the system. The recovery forecast at $31 / 12 / 2022$ will be $42.8 \%$ with cumulative oil production of 98MMSTB. These results are necessary and important for reservoir engineers and policy makers in reservoir management.
\end{abstract}

Keywords: Performance, Reservoir, Dominant Energy, Production, Recovery, Prediction

\section{Introduction}

The roles of Reservoir engineers are to continuously monitor the reservoir, collect relevant data and interpretthese data to be able to determine the present conditions of the reservoir, estimate future conditions and control the flow of fluids through the reservoir with an aim to increase recovery factor and accelerate oil recovery [1]. It therefore implies that the ability of a Reservoir engineer to predict the behaviour of petroleum reservoirs depends solely on his ability to predict the flow characteristics of the fluids in the reservoir. Thus, the main concern of the engineer to carry out a study on the reservoir is to adequately simulate the reservoir with minimum effort [2]. In real-life scenario, the knowledge of a reservoir is not accurately known since the reservoirs are large complex systems with irregular geometries that are found in subsurface formations with several uncertainties, limited information about the reservoir structure and behavior [1]. Reservoir fluid properties are very important in petroleum engineering computations, such as material balance calculations, well test analysis, reserve estimates, inflow performance calculations and numerical reservoir simulations [3]. Ideally, reservoir PVT properties are determined from laboratory studies on samples collected from the bottom of the wellbore or at the surface [4]. Such experimental solution is to use the empirically derived correlations to predict PVT properties.

Conventional reservoir engineering procedure is inadequate for the analysis of an oil reservoir which has considerable and complex structural relief, steep, andgood permeability. In this type of reservoirs, gravity drainage plays a major role in the movement of oil to producing wells and this should be included in the analysis and prediction of the reservoir behavior. It is a general belief by engineers that the force of gravity is only important in the later life of a reservoir. This may be due to the fact that gravitational effects may not be easily detected [5]. Actually, the effects of gravitational forces are at a maximum when the reservoir pressure is high. But recent approaches have now been adopted for the analysis and prediction of reservoir performance, especially the use of material balance [6].

Material balance is an analytical tool that allows the analysis, evaluation and prediction of the performance of hydrocarbon reservoir system [7]. The ease with which the 
material balance technique can be applied allows for faster decision making concerning oil and gas reservoir management compared to 3D numerical simulation [8]. The material balance equation (MBE) carries out resource volume allocation by considering the different time intervals in the depletion history of a reservoir ensuring volumes conservation [9]. The Havlena and Odeh straight line technique is one of several methods developed that apply the material balance equation (MBE) to different reservoirs. An important evolution of MBAL is the application of multi-tank evaluation [10]. The MBAL multi-tank model is regarded as an approximate model to a full field model for developed reservoirs in communication with undeveloped reservoirs [9]. The use of MBAL to investigate communication of reservoirs due to sand to sand juxtaposition of reservoirs based on fault seal analysis is due to the availability geologic data [8]. MBAL had already been used to determinereserves for developed and producing reservoirs that are in communication via non-sealing faults [9]. It has also been used in reservoirs evaluation of developed reservoirs that have been compartmentalized due to intra reservoir shale [11]. Most reservoirs in the Niger Delta fall into these categories due to complex faulting, hence the use of multi tank model to provide a better description of our reservoirs [10]. This method has been used to evaluate the impact of inter reservoir communication between two reservoirs. It was adopted due to shorter simulation time to use the information to make management decisions and future development plans [11].

In this work, we carried out performance prediction of Niger Delta reservoir BUZA using MBAL (Allocation tool). This was necessaryto determine with reasonable certainty, the expected recovery of the reservoir due to the uncertainties and complexities that characterize the description of the volume of fluid present in a reservoir which forms a very important part of reserve development, reservoir management and decision making. This was achieved by building a single tank model; thereafter the empirical fluid property correlations were adjusted to fit measured PVT laboratory data, then the uncertain reservoir and aquifer parameters were estimated using the non-linear regression approach of the MBAL and finally the accuracy of the model was validated by history matching the field pressure and production data with the simulated data.

\section{Methodology}

This study investigates the performance prediction of Niger Delta reservoir BUZA using MBAL (Allocation tool). This was achieved by building a single tank model.

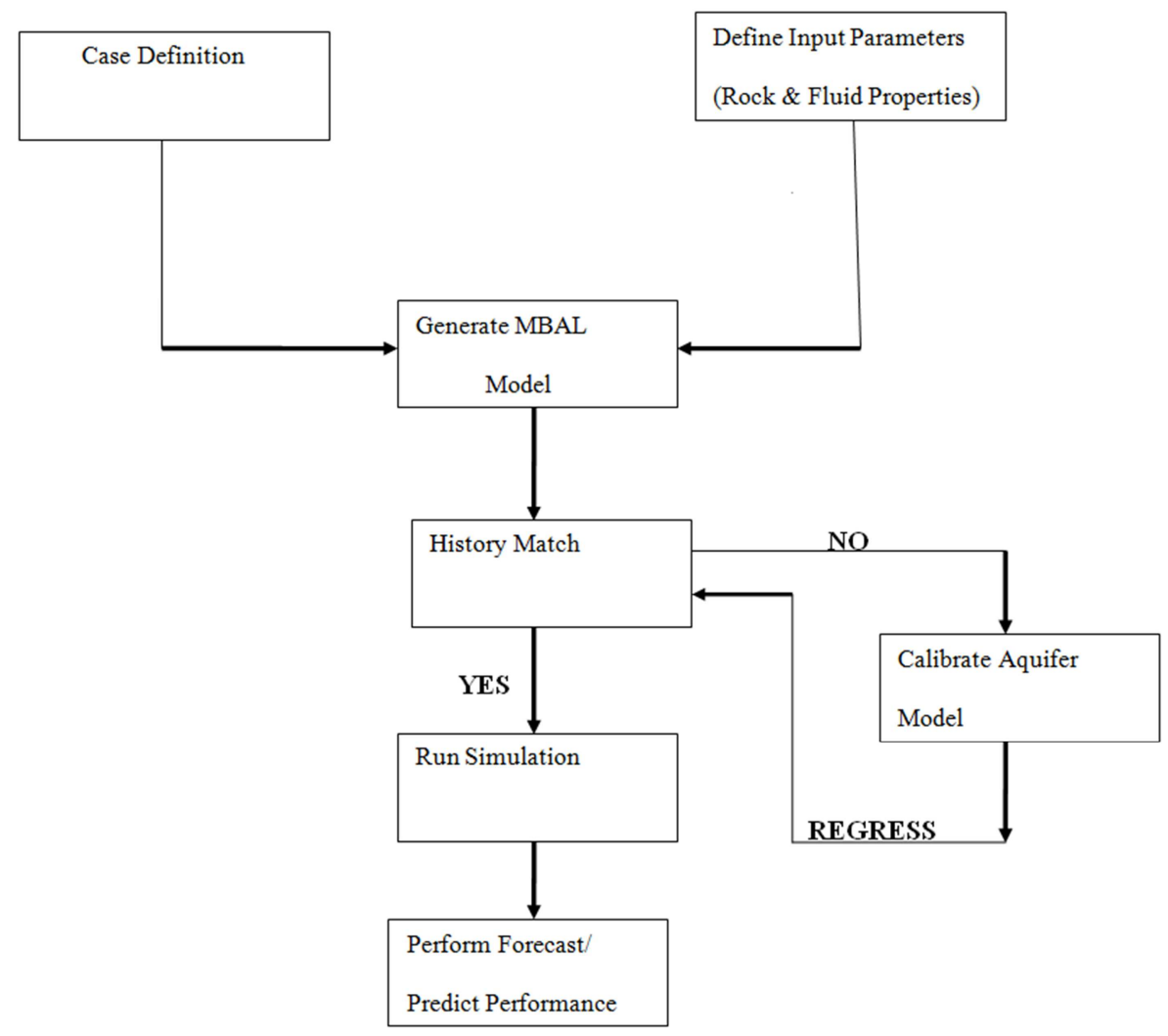

Figure 1. Workflow for MBAL Model.

\subsection{Workflow Procedure}

i. Pressure and production data were entered on a single tank basis. ii. The matching facility in MBAL was used to adjust the empirical fluid property correlations to fit measured PVT laboratory data. Correlations were modified using non-linear regression technique to best fit the measured data. 
iii. The graphical method plotwas used to visually determine reservoir and aquifer parameters. The Campbell plot of the graphical method was used to visually observe and determine the appropriate model and parameters.

iv. The non-linear regression engine of the analytical method was used to estimate the uncertain reservoir and aquifer parameters and fine tune the pressure and production match. This was done for various aquifer models with the best match with actual field data selected.

v. The accuracy of the model was validated by history matching the field pressure and production data with the simulated data.

\subsection{Input Parameters}

The input data into the MBAL model include production and pressure data, PVT properties, aquifer parameters, reservoir thickness, relative permeability data. Porosity and permeability input data were obtained from well logs via averaging method. Correlations were used to evaluate relative permeability. A summary of the input data and relative permeability data that used for this studyareshown in table 1 and 2 respectively.

Table 1. Summary of input data.

\begin{tabular}{ll}
\hline PARAMETER & INPUT \\
\hline FORMATION GOR (SCF/STB) & 476 \\
OIL GRAVITY (API) & 26 \\
GAS GRAVITY (SP. GRAVITY) & 0.7 \\
WATER SALINITY (PPM) & 33000 \\
MOLE PERCENT H2S & 0 \\
MOLE PERCENT CO2 & 0 \\
MOLE PERCENT N2 & 0 \\
BUBBLE POINT PRESSURE (Psig) & 3587.7 \\
OIL FVF (RB/STB) & 1.24 \\
OIL VISCOSITY (cp) & 1.3 \\
\hline
\end{tabular}

Table 2. Relative Permeability data.

\begin{tabular}{llll}
\hline & Residual saturation & End point & Exponent \\
\hline Krw & 0.05 & 0.4 & 1.8 \\
Kro & 0.2 & 0.85 & 0.9 \\
Krg & 0.08 & 0.95 & 1.35 \\
\hline
\end{tabular}

\section{Overview ofthe Reservoir}

The reservoir under study (BUZA) is situated in the Niger Delta in the South-South part of Nigeria. The reservoir is under-saturated and has bubble point pressure of $354 \mathrm{psia}$. The reservoir has an API gravity of 21.88 and oil density of $63.12 \mathrm{lb} / \mathrm{ft} 3$ and rock compressibility of $1.04134 \mathrm{E}-6$. Just like other nearby reservoirs in the same field, BUZA-307 has a high permeability.

\section{Case Definition}

A single tank MBAL model was built [12]. Several aquifer influxes were modeled from which a suitable match representative of reservoir trend was selected. The models were initialized and pressure match carried out by regressing on parameters with uncertainty as shown in figure 2

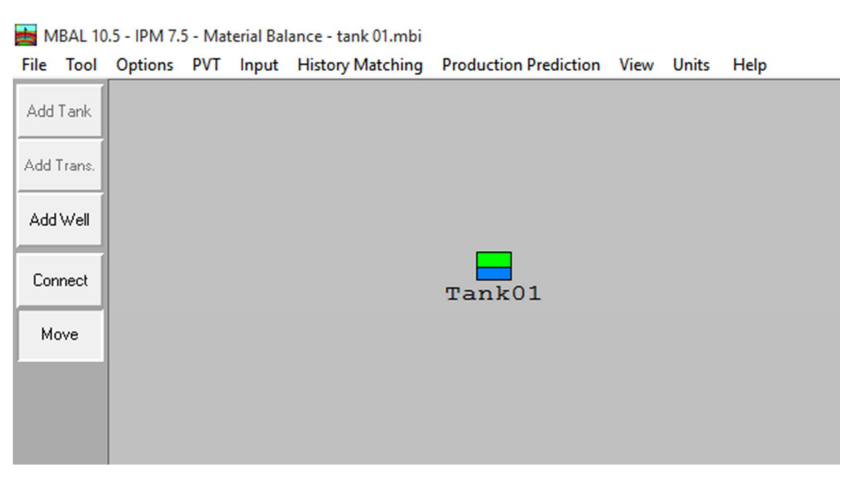

Figure 2. Single tank MBAL model.

\subsection{MBAL Model}

The quality assured data gathered were used to initiate the MBAL model. Knowledge of the reservoir structure and aquifer strength based on available data were used to ensure good engineering judgment to build the model.

\subsection{History Matching}

The single tank model constructed was history matched with reservoir production and pressure data. This was done with aquifer parameters being the key uncertainty; the encroachment angle and radius were regressed upon to obtain history matches on pressure and production data. The main criterion used to assess the quality of the matches is to obtain a satisfactory pressure match for the tank.

\subsection{Aquifer Model}

During the study, to get a good history match, several aquifer models were attached to the reservoir model and their parameters were regressed upon. The aquifer model that best describe the physics and geology of the system was selected; this is observed when the model replicated the reservoir behaviour to a reasonable extent.

\subsection{Simulation and Prediction}

After a good history match had been achieved, measured reservoir pressures were compared with the MBAL simulated pressure to see how good the model could replicate the prevailing reservoir pressure given the same energy, rock and fluid properties. The MBAL model showed a good pressure match for the tank with actual production and pressure data. This was then used as a basis to predict the performance of the reservoir.

\section{Results and Discussion}

\subsection{The Energy of the System}

After a suitable aquifer was selected, the relative contributions of the main source of energy in the reservoir and aquifer systems contributing to the recovery from the reservoir were ascertained. From figure 3 , it is observed that 
there are four drive mechanisms present with the pore volume compressibility and the fluid expansion beingignored due to the negligible fraction of energy they contribute. Water injection was identified as the dominant energy in the system and contributed about $68 \%$ of of the total energy in the system while water influx contributed about $30 \%$ of the energy. Hence, it can be concluded that the main source of energy comes from water injection with little support from the aquifer.

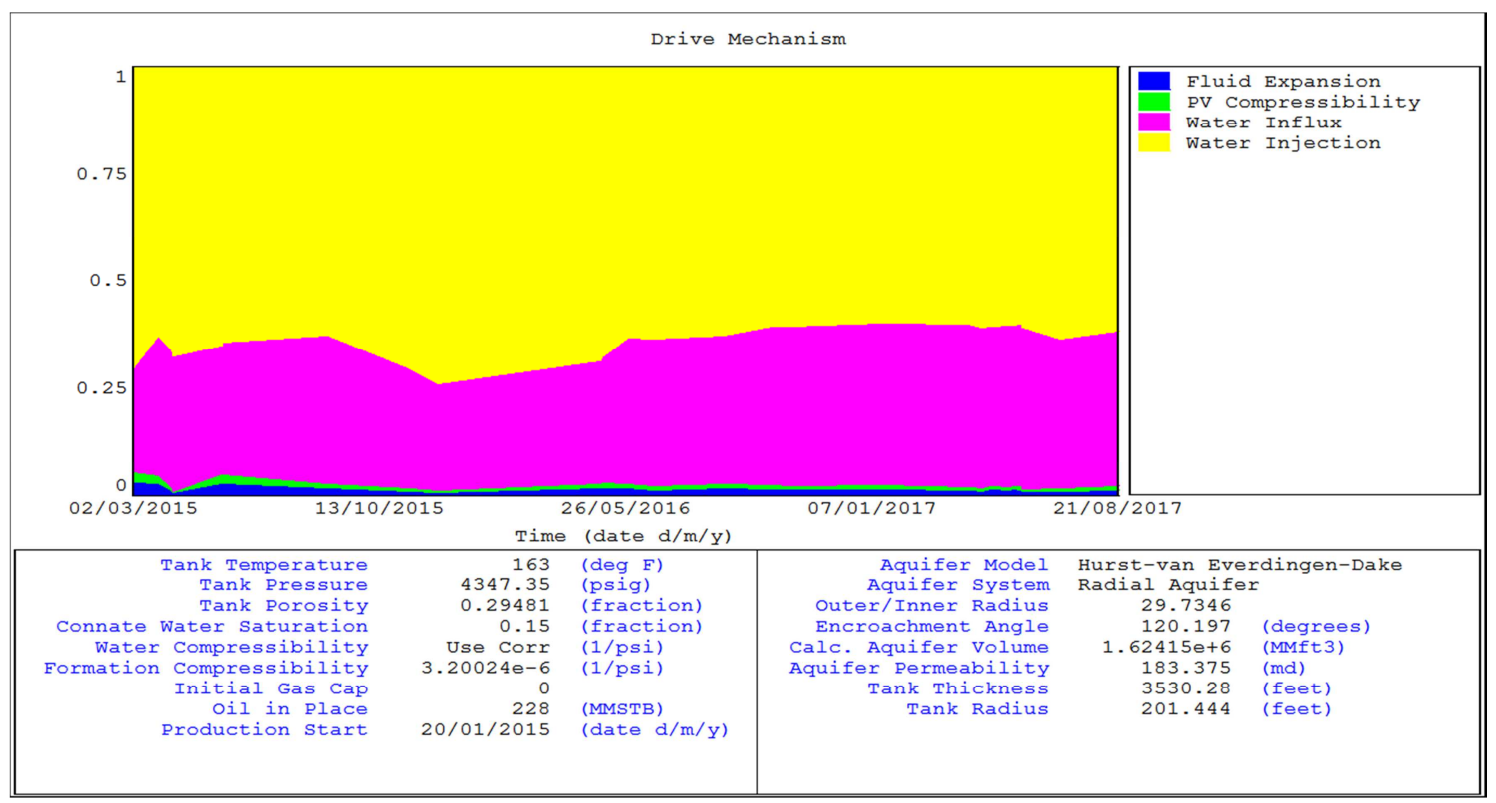

Figure 3. Drive mechanism for reservoir BUZA.

\subsection{Simulation}

The analytical plot uses the reservoir pressure entered in the historical data to calculate the production while simulation does the opposite. The rates are used from the historical data and the reservoir pressure is calculated based on the material balance model. Figure 4 show that the Hurst- van Everdingen-Dake aquifer model simulated the reservoir pressure decline better than the other models selected due to the fact that pressure decline is approximated as a series of time steps with constant pressure. The constant pressure comes from water injection since we have a relatively weak aquifer system.

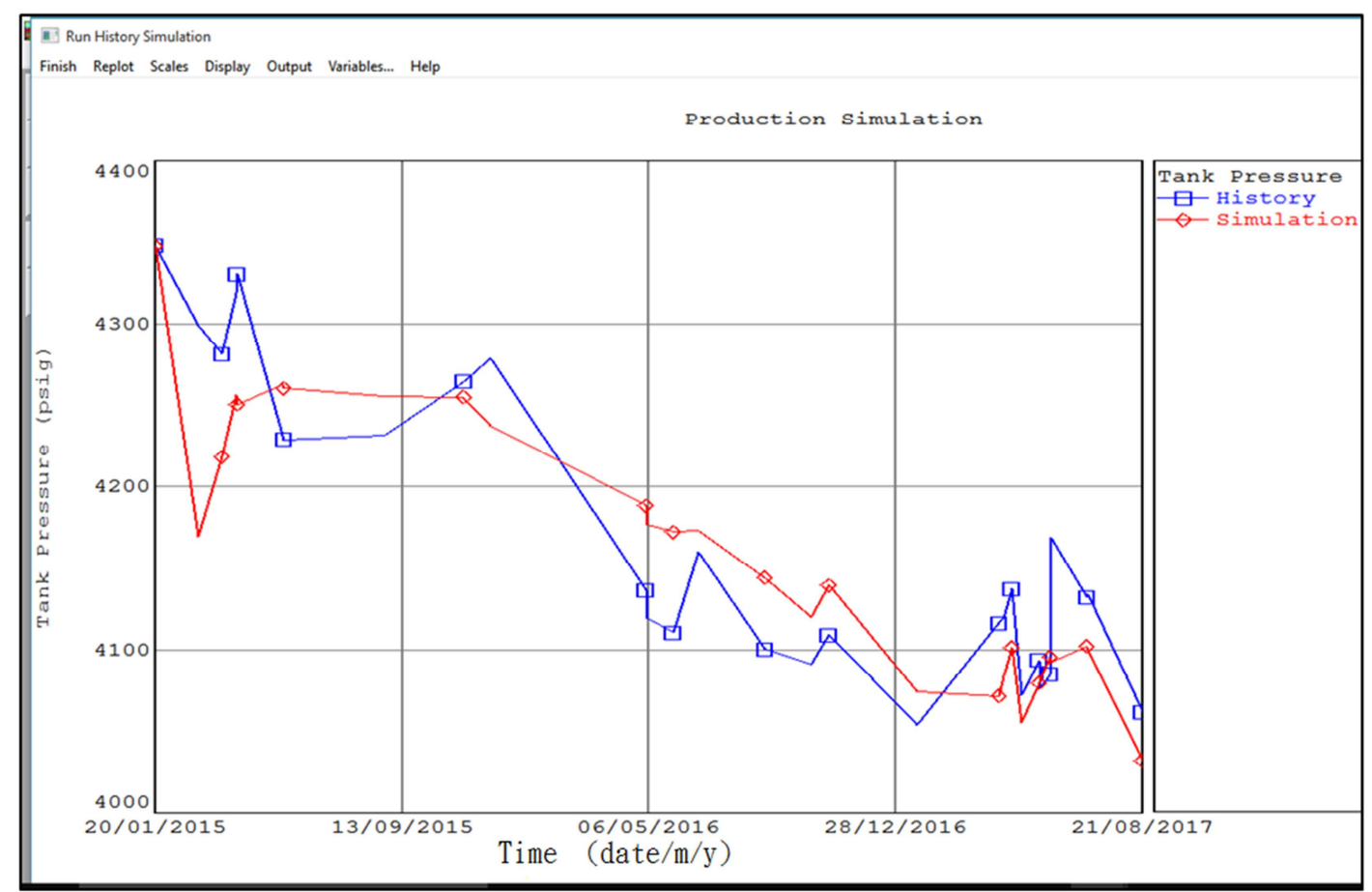

Figure 4. Simulation result for reservoir BUZA. 


\subsection{Performance Prediction}

With acceptable pressure history match obtained, predictions on cumulative oil production, oil recovery factor, reservoir pressure decline are carried out.

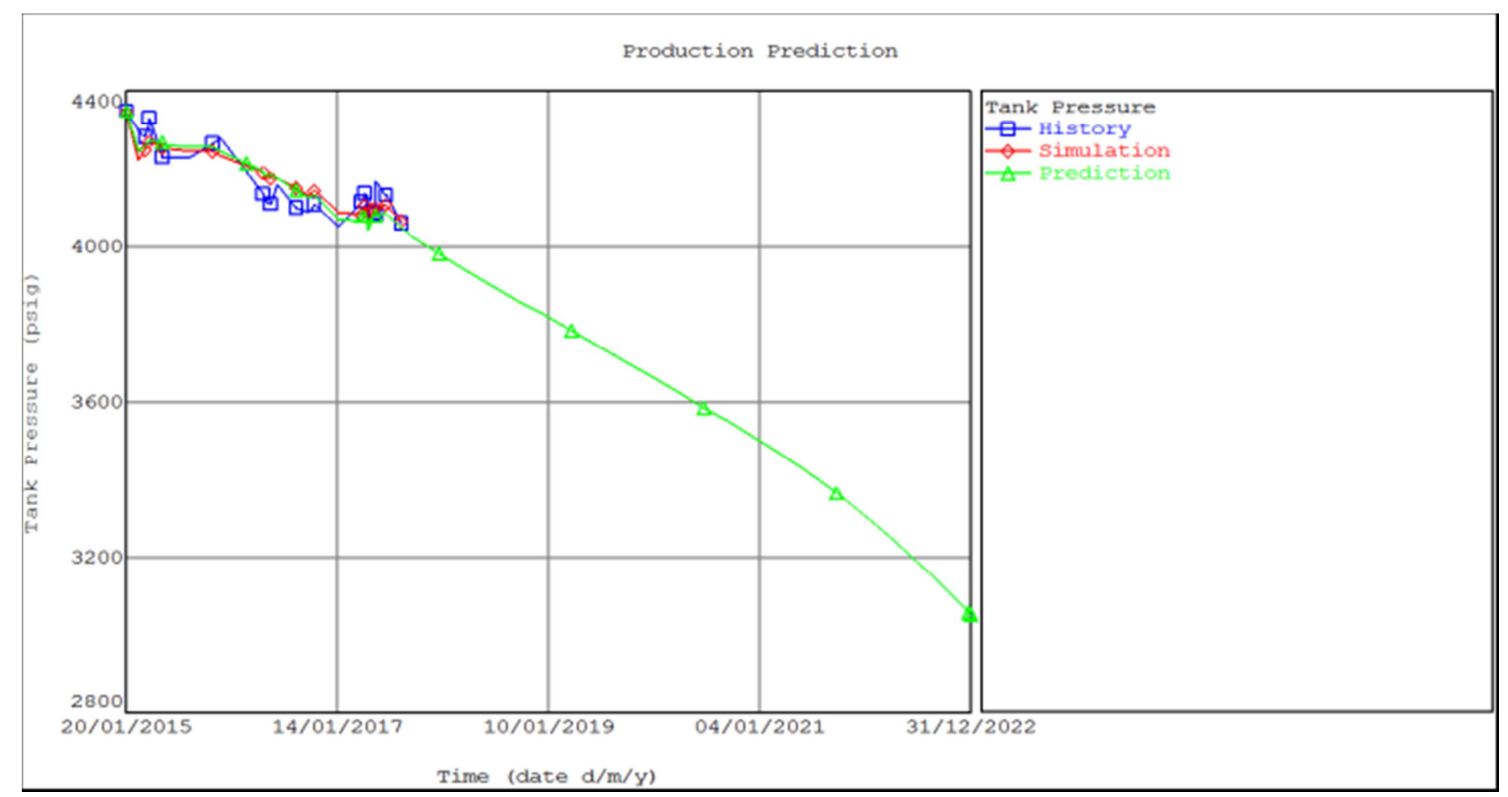

Figure 5. Tank pressure versus time.

Figure 5 shows that from the beginning of production in $20 / 01 / 2015$ to $21 / 08 / 2017$, the reservoir pressure declined from 4347.35 psig to 4069 psig, which is 278 psigreductions in reservoir pressure for over 2 years of production. From the end of historical production, 21/08/2017 to the forecast date of $31 / 12 / 2022$, which is a 5 -year period, the model predicts that the reservoir pressure will have a decline of 1014 psig (i.e. from 4069 psig to $3055 \mathrm{psig}$ ). This relatively large pressure reduction of 1014 psig over a 5-year period compared to the initial decline of 278 psig over a 2-year period was attributed to water injection reaching its economic limit or a reduction in the average water injection rate.

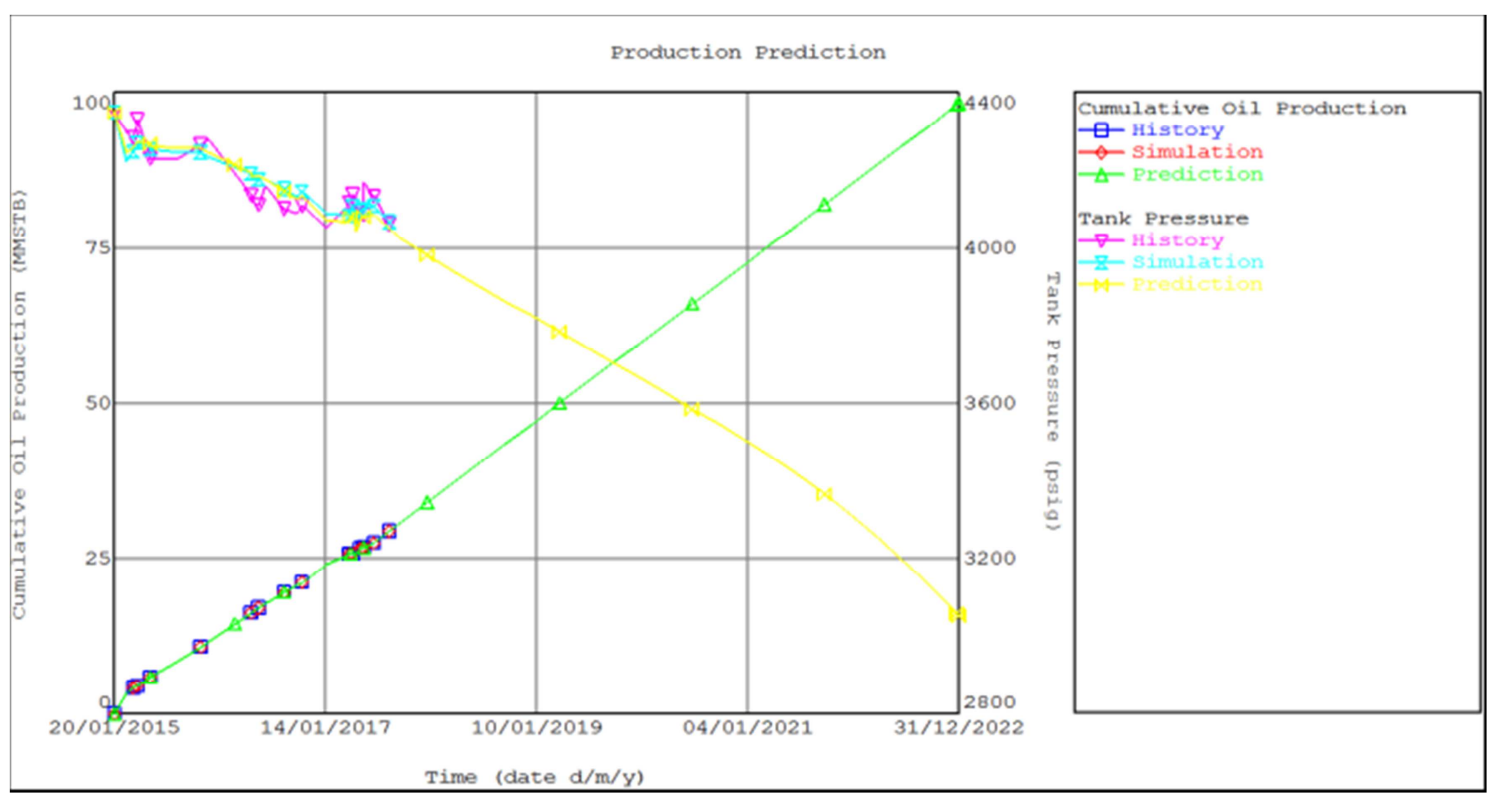

Figure 6. Cumulative oil production with tank pressure versus time.

From figure 6, it was observed that the cumulative oil produced from the beginning of production to the end of historical production was29.29 MMSTB which is only $12.8 \%$ of total recoverable reserve (228 MMSTB) for a $278 \mathrm{psig}$ reservoir pressure decline. The model forecasts that cumulative oil produced will be about 98 MMSTB, meaning that an additional 69 MMSTB $(30 \%)$ of oil will be produced at the forecast date of $31 / 12 / 2022$. This shows that the 
reservoir pressure decline of 1014 psig within 5 years resulted in more oil production compared to the reservoir

pressure decline of 278 psig within a 2-year period.

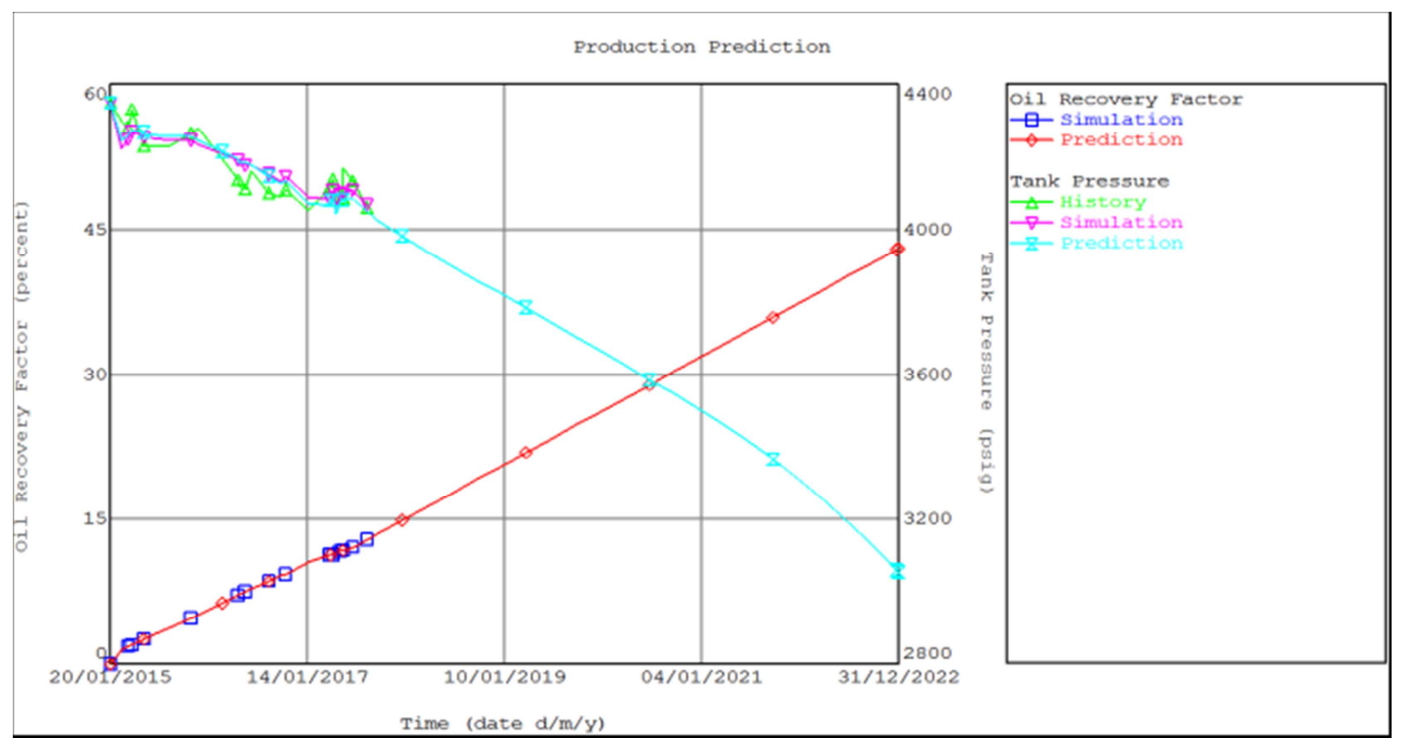

Figure 7. Oil recovery factor with tank pressure versus time.

From the beginning of production in 20/01/2015 to the end of historical production period, 21/08/2017, the recovery factor stood at $12.8 \%$ while the model forecasts the recovery factor to increase to $42.8 \%$ at the forecast date of $31 / 12 / 2022$ as shown in figure 7 , which is an average of $6 \%$ per year increase in recovery factoragain shown in figure 8 . This means constant average water injection rate of about 22000 STB/day would be maintained since water injection is the dominant energy in the system.

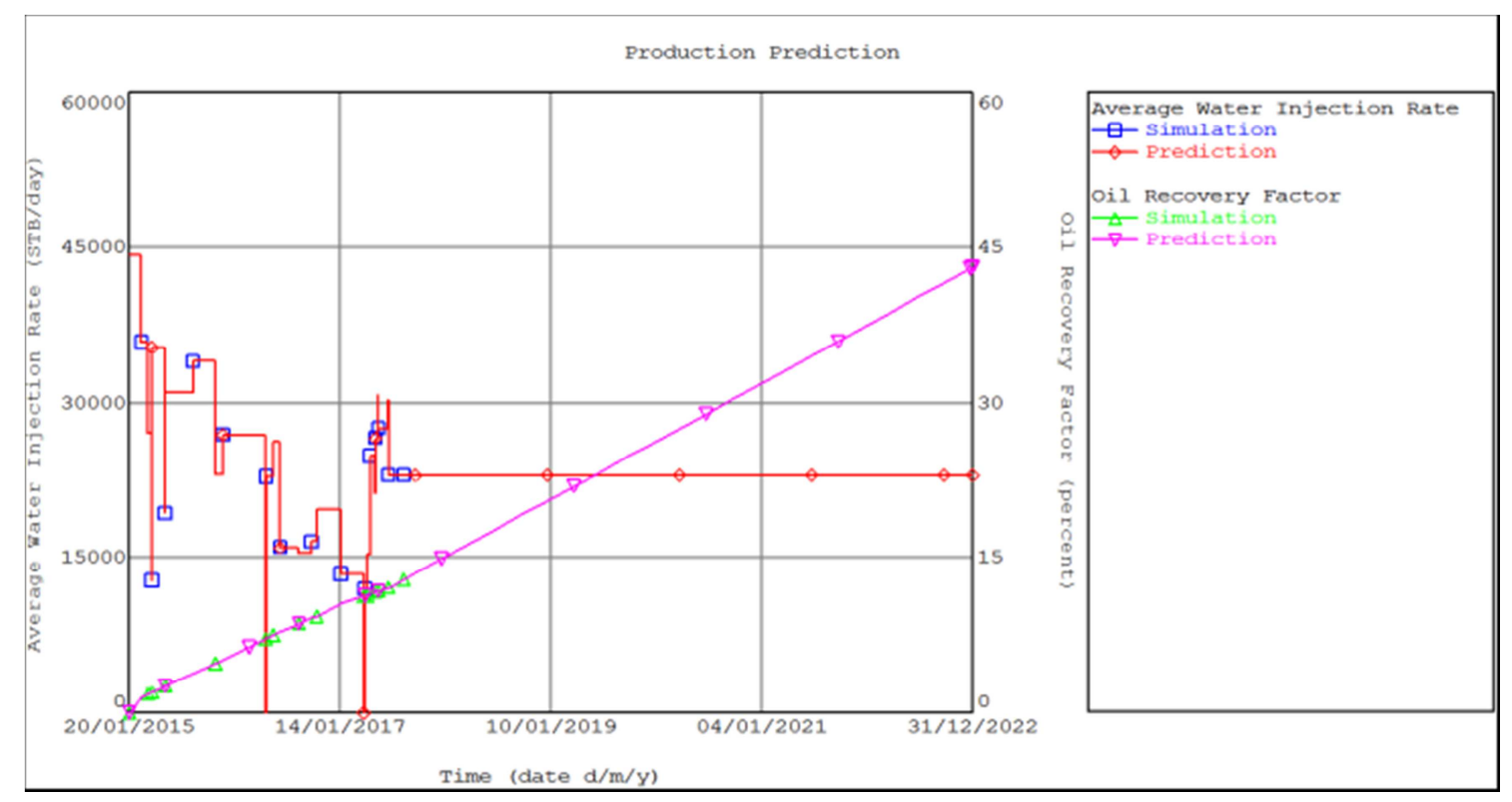

Figure 8. Average water injection rate and oil recovery factor versus time.

\section{Conclusion}

From the results obtained the following conclusions are drawn from this work:

The material balance analysis has proved to be a useful investigative tool when time is limited. It has also proved to be a very fast analytical tool in evaluating resource volumes for reservoirs with historical production. Good data acquisition is required to carry out reserve evaluation with MBAL as it is used to initialize, calibrate and benchmark the history matching.

The main source of energy in reservoir BUZAwas water injection, providing about $68 \%$ of the reservoir energy required for oil recovery from the reservoir. The Hurst-van Everdingen-Dake model best described the reservoir BUZA aquifer which provides about $30 \%$ of the reservoir energy.

The cumulative oil produced for the historical period was 
29.29 MMSTB and 98 MMSTB for the forecast period, with recovery factors of $12.8 \%$ and $42.8 \%$ respectively. The recovery for the forecast period is achievable assuming an average water injection rate of $22000 \mathrm{STB}$ /day is maintained.

\section{References}

[1] Holstein, E. (2007). Petroleum Engineering Handbook: Reservoir Engineering andPetrophysics. Texas: Society of Petroleum Engineers.

[2] Mohammed, N., Ameer, S., Ali, S. (2017). Reservoir Performance Prediction Using MBAL Software: A Case Study.

[3] Gupta, J. (2010). PVT correlations for Indian Crude Oil Using Artificial Neural NetworksJournal of Petroleum Science Engineering 72 (1): p. 93-109.

[4] Osman, E., Abdel -Wahhab, A., Al-Marhoun, E. (2001). Prediction of oil PVT Propertiesusing Neural Networks. Paper SPE 68233 presented at the SPE Middle East oil show, $17-20$ March, Manama, Bahrain.

[5] Abu, M. (2007). Reservoir Characterization from Material BalanceResultsAnalysis, paper SPE108648 presented at the SPE International OilConference and Exhibition, 2 - 4 August, Veracruz, Mexico.

[6] Manzir M. P., Beka F. T. and Kadana R. I. (2015): Predicting Reservoir PerformanceChanges with Time. International
Journal for Research in Emerging Science and Technology, Volume-2, Issue-9, Sep-2015.

[7] Petrowiki. (2018). Material balance in oil reservoirs. http://petrowiki.org/material_balance_in_oil_reservoirs.

[8] Mogbolu, E., Okereke, O. (2015). Using Material Balance Single Tank Model to Evaluate Future Well Performance in Reservoirs with Distinct Geological Units. Paper SPE 178484 presented at the SPE Nigeria Annual International Conference and Exhibition, 4 - 6 August, Lagos, Nigeria.

[9] Nwaokorie, C., Ukauku, I. and Emelle, C. (2013). Material Balance Modeling of Reservoirsin a single system: case studies. Paper SPE 160988 presented at the SPE Nigeria AnnualInternational Conference and Exhibition, 29 July 2August, Lagos, Nigeria.

[10] Ogbodu, E. D. (2011). Estimation of Fluid Transmissibility and Oil Production Allocationin Faulted Multi Layered Reservoirs using Material Balance Analysis. Paper SPE 152361 presented at SPE Annual Technical Conference and Exhibition, 30 October-2 NovemberDenver, Colorado, USA.

[11] Mogbolu, E., Okereke, O., Olatope, V., Ukauku, I. (2016). Evaluation of the Impact of Inter-Reservoir Communication on Resource Volume Via Material Balance Multi TankModel. Paper SPE 184349 presented at the SPE Nigeria Annual International Conference and Exhibition, 2 - 4 August, Lagos, Nigeria.

[12] $\mathrm{MBal}^{\mathrm{TM}}$ Manual, (2007). Reservoir Engineering Tool Kit, User Guide, Version 10.5. 